\title{
PERCEPTIONS OF THE FACTORS THAT INFLUENCE THE LABOUR PRODUCTIVITY OF PROCUREMENT EMPLOYEES IN E-COMMERCE COMPANIES UNDER TELEWORK CONDITIONS
}

\author{
Ovidiu-Iulian BUNEA \\ Bucharest University of Economic Studies, Romania \\ E-mail: ovidiu.bunea@man.ase.ro
}

DOI: 10.52846/MNMK.19.2.02

\begin{abstract}
:
This study investigates several factors that underlie the perception of procurement employees in e-commerce companies, regarding labour productivity in the context of telework during the COVID-19 pandemic. For this, we used a representative sample of 134 companies with e-commerce activity in Romania. Thus, with the help of multiple linear regression, relevant influences were identified between the level of autonomy of the employee, called discretion-to-work, working conditions provided by the employer, employee life satisfaction and productivity perceived by them under telework conditions. Generally, we notice positive effects of telework on employees' perceptions of productivity.
\end{abstract}

Keywords: telework, work from home, labour productivity, COVID-19, procurement, e-commerce.

\section{Introduction}

Telework, in a broad sense, can be characterized as a professional activity conducted in a location other than conventional, the employee being connected to the employer's computer systems through established means and telecommunication technologies (Aguilera et al., 2016). As a concept, telework has made its presence felt since the $70 \mathrm{~s}$, in the context of the oil crisis, to reduce the costs of companies. The practice and the specialized literature, however, show that teleworking is still a difficult term to define and quantify because it can refer to varied situations in which the employee finds himself, in terms of technologies available to conduct his specific activity, geographical location or contractual terms. The reasons for resorting to telework are diverse, in a recent study, Kazekami (2020) illustrates that the Japanese encourage telework, given that the country is facing a shortage of labour in certain areas caused by declining demographics. In this sense, telework encourages the elderly and women to work, facilitating their access to work and ensuring the balance between family and professional life. In this paper, we will consider telework as a paid activity, which, under normal conditions, could occur in a space provided by the employer, but which occurs at the employee's residence. Thus, the notion of telework that we use, illustrates the work done from home. Furthermore, in the context of this particular research we refer only to specific procurement activities that can be performed from home such as those related to the identification and selection of suppliers. Looking at telework this way, we avoid the 
risk of confusing pandemic telework with work that would normally be based on other principles, and we can focus on the effects of telework during the COVID-19 pandemic. The COVID-19 pandemic has affected all aspects of people's lives, from economics to social interaction, turning telework into a necessity in response to companies to an unprecedented situation.

According to Aguilera et al. (2016), employees who performed telework activities from home had a low share in the total number of employees, both in Europe and in the United States of America. Although teleworking did not develop very rapidly despite the expected imminent benefits, business conditions changed rapidly and dramatically, with the sudden change in some variables caused by the COVID-19 pandemic, which caused an explosion of this approach on work. Therefore, telework has become mandatory for many categories of employees with the global spread of coronavirus, telework being seen in context as an effective and efficient measure to continue the work of a countless number of employees. We can think that it is possible that after the end of this pandemic, many categories of employees will continue to work under the same conditions, at least part-time (Zhang et al., 2020). Given the context, we find the opportunity to closely research the theoretical foundations of telework, complementing it with empirical analysis in an attempt to contribute to the development of telework. Several studies have analysed telework and its implications in Romania, but consistent quantitative analysis on this topic seems to be lacking, especially since, so far, the development of work in such conditions has been the exception and not the rule. Thus, today we have more chance than ever to research these issues, given that we are all part of a global experiment caused by the pandemic. The current study investigates (1) the effects of discretion-to-work on employee's perceived labour productivity in telework conditions; (2) the influence of employee's life satisfaction on perceived labour productivity in telework conditions; (3) the implications of working conditions (as referred to teleworking during COVID-19 pandemic) on employee 's perceived labour productivity in telework conditions; (4) the impact of telework on employee's perceived labour productivity in telework conditions.

This paper is structured in five sections. The first section contains the results of the study of the literature on the topic, considering both theoretical and empirical studies. Also, in this section we substantiated the research hypotheses. The second section presents the research methodology, where we included both the data collection method, the sampling method and the description and construction of the research variables. In the third section of the paper, the methods of data analysis were revealed, substantiated, and applied and the empirical results obtained were described. Section four was devoted to discussions on the results obtained in the previous section, compared to previous studies. The validity of the research hypotheses was assessed in the same section. Section five presents the conclusions, which summarize the main results in terms of practical implications, also mentioning the limitations of the study, but also proposals for future research directions.

\section{Literature review}

This section of the paper aims first to describe work from home as telework and second to identify the elements of employee perception, which can have a positive 
impact on labour productivity, and will be empirically tested in the context of procurement employees from Romanian e-commerce companies.

Many studies indicate a positive impact of telework in general and work from home, on the grounds that thanks to telework, employees can adapt their schedule and place of work, depending on needs (López-Igual \& Rodríguez-Modroño, 2020), resulting in greater autonomy at work. Some studies have shown that giving the employee some autonomy to plan, organize and perform work tasks influences the level of labour productivity, even when the employee does not work in telework (Kazekami, 2020). Moreover, Kazekami (2018) identifies the fact that employee autonomy, which we will continue to call discretion-to-work, can partially increase labour productivity under certain conditions. For this reason, we chose to introduce discretion-to-work as an independent variable of our study. Given that studies indicate a relationship with labour productivity, although only under certain conditions, our hypothesis will be:

H1. Discretion-to-work influences the perception of labour productivity of procurement employees in e-commerce companies, in the context of telework.

If in the past the interest to invest in new technologies and managerial practices necessary for telework was low (Bhattacharya \& Mittal, 2020), the present outlined by the changing working conditions caused by emergencies such as COVID-19 aroused interest in such investments to deal with this special situation. Given that telework, seen as work from home, requires the existence of infrastructure and technology to support this activity, the employee will have to benefit from minimum conditions to work in this context, such as electricity, connection to the Internet, laptop/PC or other technological solution that allows connection to the company's infrastructure. The emergency caused by the COVID-19 pandemic gives us the opportunity to study whether the lack of a traditional office creates difficulties for employee productivity in the context of telework. As an increasing number of employees around the world are forced to adopt teleworking practices while working from home, their perceptions and experiences become a prolific research topic. In a study by Mitra and Shaw (2021), they point out that in this new context, organizations need to be creative to ensure employee productivity and strategic goals. Moreover, the two authors mention the settlement of employees' expenses with the organization of a home office and its use invoking a questionnaire administered by Linkedln, whose respondents reported in a proportion of $60 \%$ that they expected employers to cover their additional expenses generated by work from home, but according to Marcellus (2020), only one in ten employers said they were open to cover these expenses. Thus, the hypothesis of our research becomes:

$\mathrm{H} 2$. Ensuring working conditions by the employer positively influences the perception of labour productivity of procurement employees in e-commerce companies, in the context of telework.

Employee life satisfaction, by which we mean a self-assessment of his life as a whole, is a variable very often used in the literature when discussing perceptions of personal well-being. Numerous studies support the idea of the opportunity to use this variable as a determinant of labour productivity (Kazekami, 2020; DiMaria et al., 2020). Also, a study by Coelho et al. (2020), pointed out that Brazilian employees perceive among the advantages of teleworking both the flexibility of the work schedule and the autonomy they enjoy in conducting tasks, but also the 
improvement of their quality of life. Thus, given the pandemic context of this study, a context in which people have reflected more than ever on all aspects of their lives, we propose the following hypothesis:

H3. Employee life satisfaction influences the perception of labour productivity of procurement employees in e-commerce companies, in the context of telework.

History of telework indicates that it has been promoted as bringing many benefits such as the potential to reduce traffic and thus congestion in large cities (Chakrabarti, 2018; Lachapelle et al., 2018; Asgari et al., 2019), but also other benefits of which we can mention an increased autonomy of the employee at work, a boost of morale, a better balance between professional and personal activity and the reduction of constraints caused by elements of space and time, imposed by a traditional work program (Bailey \& Kurland, 1999; Golden et al., 2008; Illegems \& Verbeke, 2004; Jaakson \& Kallaste, 2010; Belzunegui-Eraso \& Erro-Garcés, 2020). Morilla-Luchena et al. (2021) show that telework has a high potential to positively influence employee satisfaction with work. Considering the abovementioned aspects, we intend to investigate the influence of telework on the perceived productivity of employees in pandemic times, and for this we build the following hypothesis:

H4. Telework has a positive impact on the perception of labour productivity of procurement employees in e-commerce companies, in the context of the pandemic.

Empirical studies (Maruyama and Tietze, 2012; Bosua et al., 2017) have shown that teleworking poses certain risks to employees both in terms of career development and in terms of family life. The springs that increase labour productivity in telework conditions are not yet very well defined. Therefore, this study seeks to investigate this issue by identifying employee perceptions of labour productivity under telework conditions.

\section{Research methodology}

\subsection{Data collection and research sample}

The data we used for this study were collected through the application of a questionnaire-distributed online because of choosing a quantitative research method, the opinion poll, using the questionnaire as a research tool. For the application of the research tool, we used the platform provided free of charge by Google, namely, Google Forms, the period in which the study was conducted being February 2-March 10, 2021.

Regarding the research sample, this study focused on the employees engaged in the procurement activity of companies that conduct e-commerce activity in Romania. The study focused on this category of employees, given the pandemic context in which it was conducted, a context in which e-commerce experienced unprecedented development, which puts great pressure on companies in general and on procurement activity in particular. Our aim was to apply the questionnaire to at least one procurement employee from each company selected as part of the study. Thus, in a first phase, we established a set of selection criteria for the companies participating in the study. These criteria considered the following aspects, which had to be met cumulatively in order for companies to be considered eligible to participate (1) NACE code 4791 (Retail sale via auction houses or via the Internet); (2) the annual turnover of at least RON 100,000; (3) a minimum number of 10 employees; (4) the company to be active at the time of the study. Corresponding to 
the second stage related to the research methodology, we used an online database, https://www.romanian-companies.eu/ (2021), where we applied the abovementioned criteria, thus resulting in 177 companies that fit according to our criteria. Thus, the questionnaire was applied to a statistical population of 177 companies, with 134 valid answers received.

Going further, it was necessary to establish whether the research sample, respectively, the valid answers received are representative of our statistical population. In this regard, the literature (Krejcie \& Morgan, 1970; Dupont \& Plummer, 1990; Dell et al., 2002; Weinberg \& Kleinman, 2003; Singh \& Masuku, 2014; Boddy, 2016) provides several methods by which one can determine the representativeness of the research sample, depending on the field of research and many other phenomena that may manifest throughout the research process. We considered that the appropriate method for our study is that of statistical tables developed by Krejcie and Morgan (1970). To use this method for determining the sample size, the observation units must be between 10 and 1,000,000. For a better understanding of the method underlying the statistical tables used, we will present the determination formula:

$$
s=\frac{X^{2} N P(1-P)}{d^{2}(N-1)}+X^{2} P(1-P)
$$

Where:

$S$ - required sample size.

$X^{2}$ - the theoretical value of the chi-square test for a degree of freedom and a statistical significance level of 0,05 .

$\mathrm{N}$ - the size of the investigated group.

$\mathrm{P}$ - parameter that expresses a specific share of the population.

$d^{2}$ - degree of accuracy.

Given that our statistical population is 177 companies, we satisfy the condition of its size and moreover, according to the method for determining a representative sample presented above, its size should be 123 observation units (Krejcie and Morgan, 1970). Thus, we can conclude that this study was conducted using a representative research sample with 134 valid responses recorded.

Of the total respondents: $61.19 \%$ were women, $38.81 \%$ men; $53.73 \%$ were aged between 18 and 29 years, $41.79 \%$ between 30 and 49 years and only $4.48 \%$ were aged between 50 and 65 years; $89.55 \%$ had higher education and $10.45 \%$ secondary education; $82 \%$ came from urban areas and $18 \%$ from rural areas.

\subsection{Research variables}

The choice of independent variables is the result of the study of the literature, being based on previous empirical and theoretical research, which showed that there are positive influences of factors perceived by employees in telework conditions, on perceived labour productivity. Thus, the following independent variables resulted (1) discretion-to-work (with reference to employee autonomy) - (DW); (2) ensuring working conditions (working conditions at home were provided / covered by the employer) - (EWC); (3) life satisfaction (LS). These variables were constructed based on the items in the questionnaire we applied. If for the variables DW and EWC a single item from the questionnaire was used for their construction, regarding the 
variable LS five items from the questionnaire were used (time spent with friends; time spent with family; Improving social life; improving the level of communication with the family; Improving the relationship with the family), given its higher degree of complexity. In an initial phase, we included several items for the LS variable, but due to the application of the Cronbach's alpha consistency coefficient we kept only those items that ensured a better measure of internal consistency, so the five abovementioned items were proved to have a high consistency coefficient $(\alpha=.883)$, given that a level of .70 of Cronbach's alpha is considered the accepted reference level (Taber, 2018).

Regarding the dependent variable, it is substantiated with the help of an item meant to describe the perceived productivity of employees in telework (PPET). Both the independent and the dependent variables were constructed to verify the validity of the assumptions set out in the previous section of the paper and were measured using a Likert-type scale with values from 1 to 5 , where 1 - total disagreement; 5 total agreement.

The techniques and tools used to test the influences between these variables together with the results obtained, are presented in the next section of the paper.

\section{Data analysis and empirical results}

Descriptive statistics for the independent variables and the dependent variable, which were described in the previous section of the paper, are presented using Table 1. Given that the skewness is less than 2.0 and the kurtosis has a value of less than 9.0, we can assume that the data collected had a normal distribution (Schmider et al., 2010). This result is useful in the conditions in which the influences between the independent and the dependent variables will be tested using multiple linear regression.

Table 1

Descriptive statistics for the research variables

\begin{tabular}{|c|c|c|c|c|c|c|c|c|c|}
\hline & $\mathbf{N}$ & Range & Min & Max & Mean & $\begin{array}{c}\text { Standard } \\
\text { Deviation }\end{array}$ & $\begin{array}{c}\text { Coefficient } \\
\text { of variation }\end{array}$ & Skewness & Kurtosis \\
\hline DW & 134 & 4.00 & 1.00 & 5.00 & 3.79 & 1.15 & 1.33 & -.645 & -.423 \\
\hline EWC & 134 & 4.00 & 1.00 & 5.00 & 3.22 & 1.21 & 1.46 & -.132 & -.871 \\
\hline LS & 134 & 4.00 & 1.00 & 5.00 & 3.37 & 1.05 & 1.12 & -.598 & -.094 \\
\hline PPET & 134 & 4.00 & 1.00 & 5.00 & 3.59 & 1.22 & 1.50 & -.525 & -.618 \\
\hline
\end{tabular}

Furthermore, in the analysis of the collected data, we also tested the presumption of normal data distribution through the Shapiro-Wilk test to ensure that this prerequisite is fully met. The results indicated that for all research variables, the value of $p$ was greater than .05 (Shapiro and Wilk, 1965; Razali and Wah, 2011). Given that the null hypothesis considered for this type of test is that the data of the variables are not statistically significantly different from a normal distribution, the values of the Shapiro-Wilk test (DW - .142; EWC - .072; LS - .111; PPET - .081) did not reject this hypothesis, so we can assume once again that the data used in the study had a normal distribution.

\subsection{Pearson correlation}

Continuing with the analysis of the data collected by identifying the influences between the independent and the dependent variables, we performed a correlation 
analysis of the variables using the Pearson correlation. The purpose of this analysis was to verify the existence of multicollinearity between variables given that the existence of this phenomenon can create problems in terms of the level of statistical significance of the variables we will use in the multiple linear regression model (Shrestha, 2020). The results in Table 2 indicated that all research variables correlate statistically significantly with each other $(p<0.01)$. According to Cohen (2013) we are dealing with a weak correlation if the value of $r=0.10$, medium if $r=$ 0.30 and strong if $r=0.50$. Thus, we notice the existence of medium and strong correlations, the strong ones predominate. All values obtained for $r$-value are less than 0.8 , which is an indicator that the phenomenon of multicollinearity is unlikely to exist (Barton \& Peat, 2014).

Table 2

Pearson correlation results

\begin{tabular}{|c|c|c|c|c|c|}
\hline & & $\overline{D W}$ & EWC & LS & PPET \\
\hline \multirow{3}{*}{ DW } & Pearson Correlation & 1 & $.666^{\star \star}$ & $.609^{\star \star}$ & $.724^{\star \star}$ \\
\hline & Sig. (2-tailed) & & .000 & .000 & .000 \\
\hline & $\mathrm{N}$ & 134 & 134 & 134 & 134 \\
\hline \multirow{3}{*}{ EWC } & Pearson Correlation & $.666^{\star \star}$ & 1 & $.448^{* *}$ & $.628^{* *}$ \\
\hline & Sig. (2-tailed) & .000 & & .000 & .000 \\
\hline & $\mathrm{N}$ & 134 & 134 & 134 & 134 \\
\hline \multirow{3}{*}{ LS } & Pearson Correlation & $.609^{* \star}$ & $.448^{\star \star}$ & 1 & $.714^{* *}$ \\
\hline & Sig. (2-tailed) & .000 & .000 & & .000 \\
\hline & $\mathrm{N}$ & 134 & 134 & 134 & 134 \\
\hline \multirow{3}{*}{ PPET } & Pearson Correlation & $.724^{\star \star}$ & $.628^{\star \star}$ & $.714^{\star *}$ & 1 \\
\hline & Sig. (2-tailed) & .000 & .000 & .000 & \\
\hline & 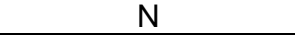 & 134 & 134 & 134 & 134 \\
\hline
\end{tabular}

\subsection{Multiple linear regression}

To test the research hypotheses, we used the variables by conducting a multiple linear regression. Thus, the aim was to identify if and to what extent our independent variables (discretion-to-work; ensuring working conditions; life satisfaction) can influence and predict the dependent (outcome) variable (perceived productivity of employees in telework). As we can see from Table 2, these independent variables are statistically significantly correlated with the dependent one, but in this stage of data analysis, we estimate how perceived productivity under telework conditions is influenced by changes within the three independent variables. Thus, the regression equation used to predict PPET using DW, EWC and LS was:

$$
\hat{P P E T}=\beta(D W) * D W+\beta(E W C) * E W C+\beta(L S) * L S-\text { Constant }
$$

Where:

PPET = estimated PPET

$\beta=$ Unstandardized regression coefficient

DW $=$ independent variable 1 - discretion-to-work.

EWC $=$ independent variable 2 - ensuring working conditions.

LS = independent variable 3 - life satisfaction. 
In Table 3, the multiple correlation coefficient between the independent and dependent variables is $R=.820$ that indicates a positive correlation between these variables. R-square $=.672$ shows that $67.2 \%$ of the variance changes of the dependent variable can be explained by the independent variables, while the remaining $32.8 \%$ remain unexplained. Adjusted $\mathrm{R}$-square $=.664$ gives us an image of the generalization level of the model, so $66.4 \%$ of the variance changes of the PPET can be predicted using the three independent variables. According to Cohen (2013), this value indicates a strong relationship.

The 95\% bootstrapped confidence interval for the slope predicting PPET from DW, EWC and LS took the following values: from .175 to .494 (DW); .097 to .368 (EWC) and from .340 to .632 (LS). Thus, we can assume that for each unit with which the DW variable increases, PPET also increases by approximately . $175-.494$ units; for each unit with which the EWC variable increases, PPET will increase by approximately. $097-.368$ and with each unit by which the LS variable increases, PPET will increase by approximately $.340-.632$ units.

Going further, the results of multiple linear regression also indicated that in general, the independent variables justify the variance changes of PPET because the results of the $F$ test are statistically significant $(p<.001)$.

Last but not least, we should mention that the values of the VIF (variance inflation factor) indicated a moderate correlation between variables, without indicating the existence of a multicollinearity problem as the values were below the maximum-accepted threshold of 5 and 10 respectively (Montgomery et al., 2021).

Multiple linear regression results

\begin{tabular}{|c|c|c|c|c|c|c|c|}
\hline \multirow[t]{2}{*}{$\begin{array}{c}\text { Variable } \\
\mathbf{s}\end{array}$} & \multirow{2}{*}{$\begin{array}{c}\text { Estimated } \\
\text { Coefficien } \\
t\end{array}$} & \multirow{2}{*}{$\begin{array}{c}\text { Standar } \\
\text { d } \\
\text { Robust } \\
\text { Error }\end{array}$} & \multirow[t]{2}{*}{ VIF } & \multirow{2}{*}{$\begin{array}{c}\text { P- } \\
\text { valu } \\
\text { e }\end{array}$} & \multirow{2}{*}{$\begin{array}{c}\text { Level of } \\
\text { Significanc } \\
e\end{array}$} & \multicolumn{2}{|c|}{$\begin{array}{c}\text { Confidence } \\
\text { Interval (95\%) }\end{array}$} \\
\hline & & & & & & $\begin{array}{l}\text { Lower } \\
\text { Boun } \\
\text { d }\end{array}$ & $\begin{array}{l}\text { Upper } \\
\text { Boun } \\
\text { d }\end{array}$ \\
\hline DW & .335 & .081 & $\begin{array}{c}2.2 \\
9\end{array}$ & .000 & $\star \star$ & .175 & .494 \\
\hline EWC & .232 & .068 & $\begin{array}{c}1.8 \\
0\end{array}$ & .001 & ** & .097 & .368 \\
\hline LS & .486 & .074 & $\begin{array}{c}1.5 \\
9\end{array}$ & .000 & ** & .340 & .632 \\
\hline \multicolumn{8}{|c|}{$\begin{array}{c}\mathrm{N}=134 \\
\text { F-test }(3,130)=88.712(.000) \\
\mathrm{R}=.820 \\
\text { R-square }=.672 \\
\text { Adjusted R-square }=.664 \\
\text { coefficient had a } 1 \% \text { level of significance }\end{array}$} \\
\hline
\end{tabular}

The results of the multiple linear regression therefore indicate that the three variables chosen could describe the changes that occur in the perceived productivity of employees under telework conditions. The implications of these results will be discussed in the next section of the paper. 


\section{Discussion}

This paper identified several factors that underlie the perception of procurement employees in e-commerce companies, regarding labour productivity in the context of telework. The effects perceived by our respondents on labour productivity in the context of telework mostly correspond to the results obtained in previous studies.

Regarding discretion-to-work, understood in the sense of employee autonomy at work (Kazekami, 2018; Kazekami, 2020), our results indicated that as employees increase their autonomy at work, they will perceive that it will increase productivity. In this way the hypothesis - H1. Discretion-to-work influences the perception of labour productivity of procurement employees in e-commerce companies, in the context of telework, has been validated even in new working conditions. Whether in the pre-pandemic period, employees could choose to telework or not, the new realities forced the introduction of telework while confirming that a higher level of autonomy positively influences perceptions of labour productivity, at least in the context of our study.

Working conditions are an important factor for employee productivity whether we are talking about the actual presence in a space provided by the employer, whether we are talking about telework conditions, respectively, work from home. A study by Bhattacharya and Mittal (2020) identified an increase in employers' interest in investing in technologies needed for telework. Moreover, Mitra and Shaw (2021) pointed out that employees want employers to provide them with the necessary conditions to work from home, and Marcellus (2020) showed that only one in ten employers would be willing to cover expenses with home office organization. Our results indicate significant positive influences of the employee's perception of ensuring the necessary working conditions by the employer and the employee's perception of telework, constructing another important factor of influence. The more willing the employer is or even ensures these working conditions, the more the employee perceives to be more productive, thus validating the hypothesis - H2. Ensuring working conditions by the employer positively influences the perception of labour productivity of procurement employees in e-commerce companies, in the context of telework.

The study considered the employee's level of satisfaction with life, understood by a subjective self-assessment of life as a whole, and the results were similar to previous studies (Kazekami, 2020; DiMaria et al., 2020; Coelho et al., 2020) as it was shown that the perception of labour productivity can be influenced by life satisfaction, the study indicating a positive relationship between the two variables. In other words, the more satisfied the employee is with his own life, the more productive he will perceive to be under telework conditions, which validates the hypothesis - $\mathrm{H} 3$. Employee life satisfaction influences the perception of labour productivity of procurement employees in e-commerce companies, in the context of telework.

Over time, numerous studies have highlighted the benefits of telework (Bailey \& Kurland, 1999; Golden et al., 2008; Illegems \& Verbeke, 2004; Jaakson \& Kallaste, 2010; Belzunegui-Eraso \& Erro-Garcés, 2020). Our study also indicated the benefits of telework in terms of the variables studied, on the productivity perceived by employees. Thus, given that all three independent research variables can influence this perception of productivity, we can assume that teleworking seen as work from home, in terms of greater employee autonomy, ensuring the necessary working 
conditions and life satisfaction builds a perception of productivity for the employee, having a positive impact. For this reason and given the context and results of the study, we can validate hypothesis - $\mathrm{H} 4$. Telework has a positive impact on the perception of labour productivity of procurement employees in e-commerce companies, in the context of the pandemic.

\section{Conclusions}

Organizations around the world have faced and still face many challenges caused by this pandemic era. Some organizations have disappeared, while new ones have been built, but many of these organizations have seen the opportunity at the strategic level to adapt their strategies to the new realities of work and to thrive. Through a proactive approach, companies are more likely to survive, and even to develop through knowledge and alignment of employee needs and the factors they perceive as determinants of productivity, under telework conditions, with the needs and strategic objectives of that organization. In this sense, this study highlights some elements that, in the perception of employees, contribute to their productivity in the context of telework. Furthermore, it is the role of managers to identify the right solutions to correlate employees' perceptions with the specific needs of the organization.

From the viewpoint of some practical implications of the study, we consider that this study is useful from a double perspective: employer and public policies. From the perspective of the employer, a greater autonomy granted to the employee and creation of the necessary conditions for teleworking or bearing the expenses of creating these conditions at the employee's home, will be the prerequisites for an increased productivity. Moreover, giving the employee enough time to worry about other aspects of his life, which will increase his satisfaction with life, is another practical implication of this study for the employer, as employee satisfaction with life is another important factor for productivity. In terms of public policies, the state could support employers through projects and programs to create the conditions necessary for the proper conduct of telework. We also consider that the COVID-19 pandemic, by forcing the introduction of telework, is an important lesson for states around the world, in terms of the usefulness of telework in crisis conditions, but for employers also, who have learned that under certain conditions telework is even productive, as well as for employees who have experienced both the advantages and disadvantages of telework.

From the perspective of the limitations of this study, we can mention the fact that we focused only on the procurement activity in e-commerce, approaching the exclusive perspective of the employee, which does not allow us to generalize the results to other company activities or fields. As future research directions we can test how these employees' perceptions influence the organization's performance under telework conditions in more varied contexts and fields of activity. 


\section{REFERENCES}

Aguilera, A., Lethiais, V., Rallet, A., \& Proulhac, L., (2016), "Home-based telework in France: Characteristics, barriers and perspectives". Transportation Research Part A: Policy and Practice, 92, pp. 1-11. http://dx.doi.org/10.1016/j.tra.2016.06.021.

Asgari, H., Jin, X., \& Rojas IV, M. B., (2019), "Time geography of daily activities: A closer look into telecommute impacts". Travel Behaviour and Society, 16, pp. 99-107. http://dx.doi.org/10.1016/j.tbs.2019.04.009.

Bailey, N. B. K. D. E., \& Kurland, N. B., (1999), "The advantages and challenges of working here, there, anywhere, and anytime". Organizational dynamics, 28(2), pp. 53-68.

Barton, B., \& Peat, J., (2014), Medical statistics: A guide to SPSS, data analysis and critical appraisal. John Wiley \& Sons.

Belzunegui-Eraso, A., \& Erro-Garcés, A., (2020), "Teleworking in the Context of the Covid-19 Crisis". Sustainability, 12(9), 3662. https://doi.org/10.3390/su12093662.

Bhattacharya, S., \& Mittal, P., (2020), "The Impact of Individual Needs on Employee Performance while Teleworking". Australasian Accounting, Business and Finance Journal, 14(5), pp.65-85. http://dx.doi.org/10.14453/aabfj.v14i5.5.

Boddy, C. R., (2016), "Sample size for qualitative research". Qualitative Market Research: An International Journal, 19(4), pp. 426-432. https://doi.org/10.1108/qmr-06-2016-0053.

Bosua, R., Kurnia, S., Gloet, M., \& Moza, A., (2017), "Telework Impact on Productivity and Well-Being". Social Inclusion and Usability of ICT-Enabled Services, 201. http://dx.doi.org/10.4324/9781315677316-10.

Chakrabarti, S., (2018), "Does telecommuting promote sustainable travel and physical activity?". Journal of Transport \& Health, 9, pp. 19-33. http://dx.doi.org/10.1016/j.jth.2018.03.008.

Coelho, F. A., Faiad, C., Rego, M. C. B., \& Ramos, W. M., (2020), "What Brazilian workers think about flexible work and telework?". International Journal of Business Excellence, 20(1), pp. 16-31. https://doi.org/10.1504/JJBEX.2020.104842 .

Cohen, J., Cohen, P., West, S. G., \& Aiken, L. S., (2013), Applied multiple regression/correlation analysis for the behavioral sciences. Routledge. http://dx.doi.org/10.4324/9781410606266.

Dell, R. B., Holleran, S., \& Ramakrishnan, R., (2002), "Sample size determination". ILAR journal, 43(4), pp.207-213. https://doi.org/10.1093/ilar.43.4.207.

DiMaria, C. H., Peroni, C., \& Sarracino, F., (2020), "Happiness matters: productivity gains from subjective well-being". Journal of Happiness Studies, 21(1), pp. 139160. http://dx.doi.org/10.1007/s10902-019-00074-1.

Dupont, W. D., \& Plummer Jr, W. D., (1990), "Power and sample size calculations: a review and computer program". Controlled clinical trials, 11(2), pp. 116-128. https://doi.org/10.1016/0197-2456(90)90157-w. 
Golden, T. D., Veiga, J. F., \& Dino, R. N., (2008), "The impact of professional isolation on teleworker job performance and turnover intentions: does time spent teleworking, interacting face-to-face, or having access to communicationenhancing technology matter?". Journal of Applied Psychology, 93(6), 1412. http://dx.doi.org/10.1037/a0012722.

Illegems, V., \& Verbeke, A., (2004), "Telework: what does it mean for management?". Long Range Planning, 37(4), pp. 319-334. http://dx.doi.org/10.1016/j.lrp.2004.03.004.

Jaakson, K., \& Kallaste, E., (2010), "Beyond flexibility: reallocation of responsibilities in the case of telework". New Technology, Work and Employment, 25(3), pp.196-209. http://dx.doi.org/10.1111/j.1468-005X.2010.00248.x.

Kazekami, S., (2018), "Does teleworking improve labour productivity". In Presented at 27th Eurasia business and economics society conference on January 11th 2019.

Kazekami, S., (2020), "Mechanisms to improve labour productivity by performing telework". Telecommunications Policy, 44(2), 101868. http://dx.doi.org/10.1016/j.telpol.2019.101868.

Krejcie, R. V., \& Morgan, D. W., (1970), "Determining sample size for research activities". Educational and psychological measurement, 30(3), pp.607-610. https://doi.org/10.1177/001316447003000308.

Lachapelle, U., Tanguay, G. A., \& Neumark-Gaudet, L., (2018), "Telecommuting and sustainable travel: reduction of overall travel time, increases in non-motorised travel and congestion relief?". Urban Studies, 55(10), pp.2226-2244. http://dx.doi.org/10.1177/0042098017708985.

López-lgual, P., \& Rodríguez-Modroño, P., (2020), "Who is teleworking and where from? exploring the main determinants of telework in Europe". Sustainability, 12(21), 8797. https://doi.org/10.3390/su12218797.

Marcellus, S., (2020). 'Work from Home: Workers Called 'Greedy,' 'Petty' for Expecting Companies to Pay for Expenses," [online] Available at: $<$ https://finance.yahoo.com/news/work-from-home-workers-called-greedypetty-for-demanding-companies-pay-for-expenses-151555802.html> [Accessed 19 February 2021].

Maruyama, T., \& Tietze, S., (2012), "From anxiety to assurance: concerns and outcomes of telework". Personnel Review, 41(4), pp.450-469. http://dx.doi.org/10.1108/00483481211229375.

Mitra, A., \& Shaw, J. D., (2021), "Strategic Benefits to Help Survive and Thrive in Times of COVID-19". The Journal of Total Rewards, First Quarter 2021, pp. 3644. https://www.worldatwork.org/journal/2021/f3-Q121_JTR-strategic-benefits.pdf.

Montgomery, D. C., Peck, E. A., \& Vining, G. G., (2021), Introduction to linear regression analysis. John Wiley \& Sons.

Morilla-Luchena, A., Muñoz-Moreno, R., Chaves-Montero, A., \& Vázquez-Aguado, O., (2021), "Telework and Social Services in Spain during the COVID-19 Pandemic". International journal of environmental research and public health, 18(2), 725. https://doi.org/10.3390/ijerph18020725. 
Razali, N. M., \& Wah, Y. B., (2011), "Power comparisons of shapiro-wilk, kolmogorov-smirnov, lilliefors and anderson-darling tests". Journal of statistical modeling and analytics, 2(1), pp.21-33.

Romanian Companies, (2021), Companies List. [online] Available at: $<$ https://www.romanian-companies.eu/pagini/p1.htm> [Accessed 12 January 2021].

Schmider, E., Ziegler, M., Danay, E., Beyer, L., \& Bühner, M., (2010), "Is it really robust?" Methodology. 6(4), pp. 147-151. https://doi.org/10.1027/16142241/a000016.

Shapiro, S. S., \& Wilk, M. B., (1965), "An analysis of variance test for normality (complete samples)". Biometrika, 52(3/4), pp. 591-611. http://dx.doi.org/10.1093/biomet/52.3-4.591.

Shrestha, N., (2020), "Detecting multicollinearity in regression analysis". Am J Appl Math Stat, 8(2), pp. 39-42. https://doi.org/10.12691/ajams-8-2-1.

Singh, A. S., \& Masuku, M. B., (2014), "Sampling techniques \& determination of sample size in applied statistics research: An overview". International Journal of Economics, Commerce and Management, 2(11), pp. 1-22.

Taber, K. S., (2018), "The use of Cronbach's alpha when developing and reporting research instruments in science education". Research in Science Education, 48(6), pp.1273-1296. http://dx.doi.org/10.1007/s11165-016-9602-2.

Weinberg, J. M., \& Kleinman, K. P., (2003), "Good study design and analysis plans as features of ethical research with humans". IRB: Ethics \& Human Research, 25(5), pp.11-14. https://doi.org/10.2307/3564600.

Zhang, S., Moeckel, R., Moreno, A. T., Shuai, B., \& Gao, J., (2020), "A work-life conflict perspective on telework". Transportation Research Part A: Policy and Practice, 141, pp. 51-68. https://doi.org/10.1016/j.tra.2020.09.007. 